\title{
Correction to: An Ethics of Care Induced from Kautilya's Wisdom
}

\section{Sharda Nandram and Ankur Joshi}

\section{Correction to:}

Chapter 4 in: M. Chatterji, L. Zsolnai (eds.), Ethical Leadership, DOI 10.1057/978-1-137-60194-0_4

The online version of the original chapter was inadvertently published with incorrect affiliation of one of the authors 'Ankur Joshi'. The affiliation has been corrected in the chapter as below:

Ankur Joshi

Management Development Institute, New Delhi, India

Changed to:

Ankur Joshi

Faculty of Management Studies - WISDOM, Banasthali Vidyapith, Rajasthan, India

The updated online version of this chapter can be found at https://doi.org/10.1057/978-1-137-60194-0_4

(C) The Editor(s) (if applicable) and The Author(s) 2019 